\section{Forensic Neuropsychology}

Robert L. Heilbronner

Chicago Neuropsychology Group, Chicago, IL, USA

\section{Definition}

In its most basic sense, forensic neuropsychology is characterized as the presentation of neuropsychological evidence to address legal questions. The neuropsychologist acts, with definable foreknowledge, with the understanding that the case is a forensic one, and the roles and requirements are clearly understood at the outset, and they are quite different from the neuropsychologist as treater role. Forensic neuropsychology typically includes cases involving worker's compensation, disability determinations, educational due process within public school systems, personal injury, criminal, child custody, impaired professional fitness for duty, competency, and other cases involving adversarial administrative and judicial determinations. According to Sweet (1999), the demand for neuropsychologists' involvement in adversarial activities is a "natural outcome of the success of a strong scientist-practitioner orientation within the subspecialty of clinical neuropsychology." This approach is both a cause and format for clinicians engaging in forensic neuropsychology. The approach is a cause in the sense that scientific gathering and objective behavioral methodologies create ongoing growth in an important knowledge area. Among the relevant by-products of a scientist-practitioner approach are familiarity with disciplined scrutiny (i.e., peer review), clinical procedures emphasizing data-based decisionmaking (i.e., accountability), and comfort with hypothesis testing (i.e., objective differential diagnosis). It is a format in the sense that related methodologies and data-based knowledge are paradigmatic in ongoing forensic activities.

\section{Cross-References}

Forensic Neuropsychologist

Forensic Psychology

\section{References and Readings}

Greiffenstein, M. F. (2009). Basics of forensic neuropsychology. In J. Morgan \& J. Ricker (Eds.), Textbook of clinical neuropsychology. New York: Taylor \& Francis.

Greiffenstein, M. F., \& Cohen, L. (2005). Neuropsychology and the law: Principles of productive attorneyneuropsychologist relations. In G. Larrabee (Ed.), Forensic neuropsychology: A scientific approach. New York: Oxford University Press.

Larrabee, G. J. (2005). A scientific approach to forensic neuropsychology. In G. Larrabee (Ed.), Forensic neuropsychology: A scientific approach. New York: University Press.

Sweet, J. J. (1999). Forensic neuropsychology: Fundamentals and practice. Lisse: Swets \& Zeitlinger. 